\title{
Investigation of Factors Restraining the Implementation of Green Buildings in Mainland China
}

Zhang Xiaolu

ESCP Europe and Tongji University

|zhangxiaolu.cathy@gmail.com

In the fast deVeloping Mainland China, among the huge out the factors that restrain the development of green building in Mainland China by carrying out surveys among construction professionals and university researchers. Fifteen barriers that may affect the development of green building negatively are identified from literature review, and factor analysis of the survey result extracts five independent principle factors behind these barriers: Techniques and Finance, Green Environment, Stakeholder Involvement, Motivation, and Management. The importance of management is especially emphasized by the survey result. Furthermore, a second survey is carried out two years later to monitor the change of importance of the five factors.

\section{Keywords}

Green Performance

Contracting, Climate

Change, Highway

Construction 


\section{INTRODUCTION}

As defined in Evaluation Standard for Green Building (ESGB, GB/ T50378-2006) by China's Ministry of Construction (MOC), Green building is a practice of creating structures to provide a healthy, applicable and effective environment, and at the same time to conserve resources (energy, land, water and materials), protect the environment and reduce pollution as much as possible and thus to remain harmonious with nature throughout its life cycle.(Liu, 2011) With these environmental friendly characteristics, green building is considered to be an effective method to achieve low energy and environment consumption of construction industry and promote its sustainable development.

The number of green buildings can give an insight into the situation of green building development in Mainland China. The two most commonly used green building rating systems in Mainland China are "Leadership in Energy and Environmental Design" (LEED) by U.S. Green Building Council (USGBC) and Evaluation Standard for Green Building (ESGB) by Ministry of Construction of China (MOC).

Up to the end of 2011, there were all together 742 buildings certified by ESGB in Mainland China.(Tian et al, 2012) Meanwhile, 562 construction projects registered for LEED-NC certification, of which 131 got certification. While in the US, in 2011 alone, 17,568 buildings registered for LEED-NC certifications and 5,650 got certified; 5,969 registered for LEED-EB certification and 1,452 got certified. 3454 registered for LEED-CI certification and 2,211 got certified. (Makover, 2012)

By 2011, China's existing buildings had reached an area of more than 40 billion square meters, with an annual new construction area of 1.6 to 2 billion square meters, among which less than 400 million square meters had a green building certification and more than $95 \%$ of existing buildings were of high energy consumption. (Chou, 2011) Considering all these facts, it can be inferred that green building development in Mainland China still need great endeavour. Regarding green building development in Mainland China, much of the focus as well as emphasis to date has been put on energy and resource efficiency optimization (Yu and Kim, 2011, 2012). Therefore, carrying out a survey regarding the factors restraint green building development is necessary, and only after the figuring out of these factors, can corresponding effort and motivation plan effectively promote green building in Mainland China.

\section{Literature review}

From a review of previous studies regarding barriers restraining green building implementation, fifteen barriers have been identified as possible barriers that hinder the successful implementation of green buildings in Mainland China. These fifteen barriers are provisionally classified under four headings for subsequent questionnaire survey, as stated below and shown in Table 1.

1. Financial Factors: B1. higher cost of green buildings compared with traditional ones; $B 2$. failure to bring greater economic benefits for stakeholders.

2. Techniques: B3. higher technical difficulty in design; B4. higher technical difficulty during the construction process; $B_{5}$. deficiency of green building related technology; B6. insufficiency of stuff who are familiar with green techniques.

3. Management Factors: B7. lack of communication and collaboration between different stakeholders; B8. the asymmetric distribution between different stakeholders regarding costs and benefits; B9. lack of relevant experience of green building projects.

Green Environment: B10. insufficiency in consumer's demand for green building; B11. lack of the atmosphere to pursue green building in construction industry; B12. incompletion of green building's relevant supporting materials procurement market; B13. corresponding laws and regulations are not complete; B14 insufficient support for green building from the government; B15. society's inadequate understanding regarding green building.

\section{Research Methodologies}

Survey on factors restraining the implementation of green buildings Two hundred questionnaires, including paper version and electronic version were sent to construction professionals and university researchers in February 2012. The respondents were required to rate, with Likert scales (on a one point to five point basis), the relative importance of the fifteen barriers that they believe hinder green building's implementation in Mainland China. Till the end of May 2012, a total number of 118 questionnaires were collected.

\section{Methods of analysis}

SPSS 18 is used to analyse the data collected in the survey, and factor analysis is used as the main statistical methodology to reveal possible common threads linking the 15 barriers restraining the green buildings' implementation in Mainland China.

Before factor analysis, the quality of data collected is assessed by performing several tests and calculating indexes: reliability of the survey's Likert scale is assessed by Cronbach's alpha coefficient, which inspects into responses' internal consistency regarding the 15 possible barriers. The extent of agreement among ratings is assessed by Kendall's coefficient. And the sampling adequacy for factor analysis is tested by the Bartlett's test of sphericity and Kaiser-Meyer-Olkin (KMO) test.

Then factor analysis is performed to investigate into possible common threads linking the 15 barriers. The factor extraction method used in this survey's factor analysis is principal component 
Financial Factors

B1. Higher cost of green buildings compared with traditional ones.

B2. Failure to bring greater economic benefits for stakeholders.
Wang, 2010; Luo, 2011;Kats G, 2009; William and Dair, 2007; Griffin et al., 2010.

Ren, 2007; Liu and He, 2011.

Techniques

B3. Technical difficulty in design.

B4. Technical difficulty during the construction process.

B5. Deficiency of green building related technology.

B6. Insufficiency of stuff who are familiar with green techniques.

Management Factors

B7. Lack of communication and collaboration between different stakeholders.

Rohracher, 2001; Van Bueren et al., 2002; Griffin et al. 2010.

B8. Asymmetric distribution between different stakeholders regarding costs Xiaoling Zhang. 2011; Van Bueren et al. 2002; Griffin et and benefits al.,2010

B9. Lack of relevant experience of green building projects.

Zhang. 2011; Liu and He, 2011.
B10. Insufficiency in consumer's demand for green building

B11. Lack of the atmosphere to pursue green building in construction industry.

B12. Incompletion of green building's relevant supporting materials procurement market.

B13. Incompletion of corresponding laws and regulations.

B14 Insufficient support for green building from the government.

B15. Society's inadequate understanding regarding green building.
Ren, 2007; Griffin et al., 2010; Rohracher, 2001.

Rohracher, 2001.

Ren, 2007; Zhou and Zhang, 2007; Rohracher, H. 2001.

Zhao and Tang, 2010; Zhang, 2011.

Zhou and Zhang, 2007; Chou, 2007; Zhang, 2011.

\section{Table 1 List of Possible Barriers}

analysis, and the rotation method used is Varimax with Kaiser Normalization.

Further to the factor analysis result, the relative importance perceived by survey respondents among different factors is ranked by calculating mean scores.

\section{Results and analysis}

\section{Survey results}

Among the 118 questionnaires returned, 95 are valid questionnaires. Among respondents of these valid questionnaires, 21 respondents are engineers from construction companies ( $22 \%), 22$ respondents come from supervision or consulting companies (23\%), 19 from real estate companies (20\%), 16 from design companies ( $17 \%)$, and the remaining 17 respondents come from university (18\%).

In the 95 valid questionnaires, less than $10 \%$ of respondents claimed that green building is their primary choice. About $30 \%$ of respondents said their projects had green considerations, although green building was not a primary choice. While about $60 \%$ of respondents claimed that they will not take green building into consideration unless there are certain motivational factors or relevant requirements.

\section{Factor Analysis}

The reliability of Likert scale is assessed by Cronbach's alpha coefficient. A Cronbach's alpha coefficient larger than 0.6 indicates enough reliability, and between 0.7 to 0.8 shows that the scale measurement has reached a considerable reliability (Zhang and Tian, 
2007). For this survey, the coefficient calculation result is 0.787 , which proves that the Likert scale in survey is reliable for this study.

The KMO value of 0.674 (>0.5) indicates that among the 15 barriers, the degree of common variance is large enough for Factor Analysis. And the Bartlett's test of sphericity is used to identify whether there exists explainable relationship among these factors. The result of Bartlett's test of sphericity shows that the coefficients matrix is not an identity matrix and the sig. level 0.00 (<0.05) shows that coefficients matrix has common factor, which means the existence of explainable relationship, and is suitable for factor analysis.

From factor analysis, five principle factors which accounts for $64.53 \%$ of the variance are extracted. And the percentage that each factor occupies is illustrated in Table 2.

According to the cross-factor loadings illustrated above, the foremost five factors can be interpreted and summarized as follows:

Factor 1 Techniques and Finance: Six barriers (B1. higher cost of green buildings compared with traditional ones; B6. insufficiency of stuff who are familiar with green techniques; B3. technical difficulty in design; B4. technical difficulty during the construction process; B2. failure to bring greater economic benefits for stakeholders) are grouped together into this factor considering the strong correlations among themselves.

Judging from the percentage of covariance, the factor Techniques and Finance is the most correlative one. It is not difficult to understand: revolution and progress in green technology leads to the cost decrease of green building. On the contrary, difficulties in green building technology and lack of relevant talents lead to the cost increase of green building. Although people tend to consider technology and finance separately when studying the barriers of green building, this result indicates that they are closely related and this correlation should not be ignored.

Factor 2 Green Environment: Based on the analysis, three Barriers (B11. lack of the atmosphere to pursue green building in construction industry; B12. incompletion of green building's relevant supporting materials procurement market; and B15. society's inadequate understanding regarding green building) that are related to Green Environment, can be grouped together into the above-named factor. The link among these barriers is the construction industry environment of green building.

Factor 3 Stakeholder Involvement: Two barriers (B7. lack of communication and collaboration between different stakeholders and B8. the asymmetric distribution between different stakeholders regarding costs and benefits) are grouped under one factor, which depicts the stakeholders in common.

Factor 4 Motivation: Two barriers (B10. insufficiency in consumer's demand for green building and B14.

\begin{tabular}{|c|c|c|}
\hline & Variance $\%$ & Cumulative $\%$ \\
\hline 1 & 18.507 & 18.507 \\
\hline 2 & 16.470 & 34.976 \\
\hline 3 & 11.477 & 46.453 \\
\hline 4 & 9.234 & 55.687 \\
\hline 5 & 8.846 & 64.533 \\
\hline
\end{tabular}

Table 2 Percentage of Each Factor

insufficient support for green building from the government) are consolidated into an underlying factor: Motivation.

Factor 5 Management: Based on their inter-correlation, two barriers (B13 Incompletion of corresponding laws and regulations and B9 Lack of relevant experience of green building projects) are grouped together as Factor 5 Management.

\section{Hierarchy of the five factors}

For each factor, the average score, which indicates the factor's relative significance, can be obtained by adding up the mean scores of the barriers comprising it, and then divided by the number of barriers within that factor. As shown in Figure 1, Factor 5 Management is the most important, followed by Factor 2 Green Environment, Factor 4 Motivation, Factor 3 Stakeholder Involvement, Factor 1 Techniques and Finance in a descending order of average score.

Factor 1 Techniques and Finance: Throughout the existing literature on factors affecting green building, this factor is the most frequently mentioned and is highlighted as a primary concern. A survey carried out among more than 700 American construction professions in 2008 showed that $80 \%$ of people believe that "the higher initial cost of investment" is the primary factor restraining green building development (Kats, 2009).Similar opinion can also be seen in William and Dair (2007), Griffin et al., (2011) and Robichaud and Anantatmula's (2010)'s research. Technical difficulties of green building including technical difficulty in design and technical difficulty during the construction process are also widely discussed by researches regarding green building development. (Zhang et al., 2012) However, this survey result showed that in Mainland China, Technology and Finance are actually not a primary impending factor.

Factor 2 Green Environment Factor 2 Green Environment ranks second in significance. Case Studies 


\begin{tabular}{|c|c|c|c|c|c|}
\hline \multirow{2}{*}{ Barrier } & \multicolumn{5}{|l|}{ Factor } \\
\hline & 1 & 2 & 3 & 4 & 5 \\
\hline Barrier 3 & 0.804 & -0.110 & 0.101 & -0.187 & 0.091 \\
\hline Barrier 2 & 0.692 & 0.034 & -0.154 & 0.290 & 0.017 \\
\hline Barrier 4 & 0.685 & 0.037 & 0.176 & 0.050 & -0.017 \\
\hline Barrier 5 & 0.668 & 0.222 & -0.072 & 0.051 & 0.121 \\
\hline Barrier 6 & 0.593 & 0.389 & 0.227 & 0.201 & -0.352 \\
\hline Barrier 1 & 0.403 & 0.116 & -0.348 & 0.377 & -0.426 \\
\hline Barrier 13 & 0.031 & 0.754 & -0.107 & 0.182 & 0.147 \\
\hline Barrier 12 & 0.086 & 0.693 & 0.394 & -0.029 & -0.040 \\
\hline Barrier 14 & 0.294 & 0.585 & 0.379 & 0.012 & 0.363 \\
\hline Barrier 10 & 0.157 & -0.008 & 0.807 & 0.096 & 0.082 \\
\hline Barrier 11 & -0.122 & 0.368 & 0.677 & 0.105 & -0.081 \\
\hline Barrier 7 & 0.070 & -0.107 & 0.385 & 0.763 & 0.125 \\
\hline Barrier 8 & 0.042 & 0.447 & -0.067 & 0.698 & 0.035 \\
\hline Barrier 9 & 0.049 & 0.127 & -0.035 & 0.096 & 0.761 \\
\hline Barrier 15 & 0.325 & 0.339 & 0.289 & 0.361 & 0.451 \\
\hline
\end{tabular}

Table 3 Cross-factor Loading

of residential and mixed-use buildings in the UK have noticed that one of the most commonly recorded barrier was a lack of green environment that the stakeholders did not consider the sustainability measure (Williams and Dair, 2007). And the above analysis result also shed light on the importance of building an initiative atmosphere to adopt green building in construction industry of Mainland China. Only when the conception of green building deeply implanted in the industry will professionals take initiative to adopt green building.

Besides, green building actually has a broad definition: it means more than conservation of energy and abatement of pollution. Studies have shown that the health and productivity benefits of green building outweighs its cost premiums in energy (Issa, Rankin etc., 2010). However, apart from experts and scholars, practitioners in the

\begin{tabular}{r|r|l|l} 
Factor 1: Techniques and Finance & & & \\
\hline Factor 2: Green Eviroment & & & \\
\hline Factor 3: Stakholder Involment & & & \\
\hline Factor 4: Motivation & & & \\
\hline Factor 5: Managment & & & \\
\hline 2.500 & 3000
\end{tabular}

construction industry do not have a comprehensive understanding of green building. They tend to mainly focus on energy and water savings of green building while ignore other benefits brought by green building such as health and productivity benefits.

Factor 3 Stakeholder Involvement Stakeholder Involvement ranks fourth in significance. The complexity and multi-stakeholder characteristic of construction projects lead to the complexity of stakeholder management. In literature study, it is found that some studies claims that the largest barrier to green building development and implementation, is actually not developing necessary technologies, but disseminating it broadly due to the " lack of collaboration between different groups of professional and construction companies" (Rohracher, 2001). Another analysis in the Netherlands concerning the institutional barriers noted that major obstacles to green building development are the lack of interaction as well as cooperation 
among different stakeholders and also the asymmetric distribution regarding costs and benefits among them (van Bueren and Priemus, 2002). However, this survey result showed that in Mainland China, stakeholder involvement is not a primary restraining factor in Mainland China.

\section{Factor 4 Motivation}

The underlying factor Motivation ranks third in significance. The following statement is found in literature review: without government setting up regulatory or policy requirements, sustainability objectives would not be considered unless your goal was to create a green building (Circo, 2008). This illustrate the importance effect of regulatory and policy requirements on green building development. Although this analysis indicates that in Mainland China, motivation is not a primary concern, it is still a factor that worth attention. This is in accordance with the situation of Mainland China since the Chinese government has made continuous effort in releasing policies which promote green building's development.

\section{Factor 5 Management}

Management always plays a significant role. And the survey result showed that this factor is of primary importance in developing green building in Mainland China. China's own green building rating system- ESGB is release in 2005. Therefore, incompletion of corresponding laws and regulations and may cause problems for companies trying to adopt green building. Considering the number of green building in Mainland China and the fact that green building did not draw public attention until recent years and, not many companies have relevant experience. Lack of experience may cause difficulty in carrying out green building projects.

As the survey result showed that this factor is of primary importance. Countermeasure such as training in green project management and improving corresponding laws and regulations should be given enough attention.

\section{Viewpoint On The Five Factors} After Two Years

Two years after the first survey, the same survey is carried out between February 2014 and March 2014 to follow possible changes. 100 questionnaires, electronic version and online version were sent to construction professions. By March 2014, 34 questionnaires are collected, reflecting a response rate of $34 \%$.

The survey result shows improvements in green building attitudes: $12 \%$ of the respondents claim that green building is their primary choice. About $58 \%$ (an increase of $28 \%$ ) of the respondents say their projects have green considerations, although green building is not a primary choice for them. While about 30\% (a decrease of $20 \%$ ) of the respondents claim that they will not take green building into consideration unless there are certain motivational factors or relevant requirements.

The average rating, indicating its relative significance of Factors are calculated, as shown in Figure 2 there is just slightly change as the survey result two years ago. Factor 2 Green Environment which ranked second gained more importance, and it ranks first together with Factor 5 Management, followed by Factor 4 Motivation, Factor 3 Stakeholder Involvement, Factor 1 Techniques and Finance in descending order of their average score.

Chinese Government has always put great incentives on financial aspects.
On April 27, 2012, the Ministry of Finance and Ministry of Housing and Urban-Rural Development of People's Republic of China announced Fiscal subsidy from 45 -80 yuan per square meter subsidy for green building. However, as the two survey showed, in encouraging green building development, Chinese government should pay more attention to other aspects as well.

\section{Conclusion}

In this paper, construction professionals and university researchers' viewpoint on 15 possible barriers that may hinder the green buildings development in Mainland China are collected. And from factor analysis of their viewpoint data, five principle factors affect the successful development of green building are identified and analyzed: these factors are Techniques and Finance; Green Environment; Stakeholder Involvement; Motivation and Management. Among these factors, the survey in 2012 has identified that management is the most significant factor affecting the successful implementation of green building in Mainland China, followed by Green Environment, Motivation, Stakeholder Involvement and Techniques and Finance in descending order of their average importance. While the survey in 2014 identified Factor 2 Green Environment gaining more importance, ranking first together with Factor 5

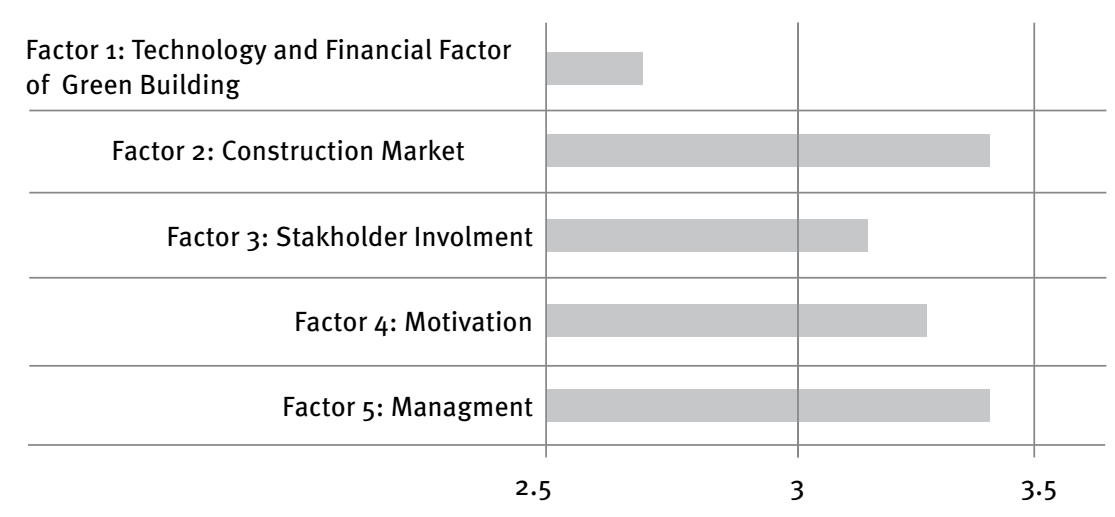

Figure 2 Average Ranking of Importance 
Management, and the rest ranking remain unchanged.

The result of this survey regarding the factor Techniques and Finance stands against opinions in many existing literatures, since this factor is the most frequently mentioned and is highlighted as a primary concern in factors hinder the development of green building. This shows the difference in green building development situation between Mainland China and other countries.

The result that the factor Management is of primary importance can be well explained by the development process of green building in Mainland China - especially late release of relevant rating standard. And it is emphasized that countermeasure to this factor such as training in green project management and provide corresponding laws and regulations should be given enough attention.

Although the data of first survey is adequate to perform statistic analysis, a larger scale of survey is recommended and the result of this study can provide reference. Furthermore, investigation and research on appropriate motivation plan for green building development in Mainland China are also recommended.

\section{References}

Circo, C. J. (2008). “Using mandates and incentives to promote sustainable construction and green building projects in the private sector: a call for more state land use policy initiatives." Penn State Law Review, 112, 731.

Chou, B. (2011). “Green building development prospect and countermeasures in China." Housing industry, 2011 (2): 10-11.

Griffin, C. T., Knowles, C., Theodoropoulos, C., and Allen, J. (2010) et al. "Barriers to the implementation of sustainable structural materials in green buildings." Structures and Architecture: Proceedings of the 1st International Conference on Structures and Architecture (ICSA2010). Guimarães, Portugal. 2010.

Issa, M. H., Rankin, J. H., and Christian, A. J. (2010). “Canadian practitioners' perception of research work investigating the cost premiums, long-term costs and health and productivity benefits of green buildings." Building and environment, 45(7), 1698-1711.

Kats, G. (2009). Greening our built world: costs, benefits, and strategies. Island Press. New York.

Li H., Miao J. (2009) Development and Reform Status on Domestic Green Building. Energy and Environment, 19: 21-22.

Liu, J. Y., Low, S. P. and He, X. (2011) Green practices in the Chinese Building Industry: Drivers and Impediments[J]. Journal of Technology Management in China, 7(1):50-63.

Liu J., He X. (2011). Influence Factors on Real Estate Companies' Decision to Develop Green Building Projects. International Economic Cooperation, 3: 82-85.

Makower, J. (2012). State of green business 2012. GreenBiz Group.

Ministry of Housing and Urban-Rural Development of People's Republic of China (MOHURD), and General Administration of Quality Supervision, Inspection and Quarantine of the Peoples Republic of China(AQSIQ). (2006) Evaluation Standard for Green Building GB/T50378-2006.

Ren Y. (2007). “Obstacles and Countermeasures in Promoting Green Building”. Development Research, 2007(10): 47-49.

Robichaud, L. B., and Anantatmula, V. S. (2010). “Greening project management practices for sustainable construction." Journal of
Management in Engineering, 27(1), 48-57.

Rohracher, H. (2001). “Managing the technological transition to sustainable construction of buildings: a socio-technical perspective.” Technology Analysis and Strategic Management, 13(1), 137-150.

Tian H., Zhang H., Sun D. et al. (2012) “Green building development in Mainland China, Current Situation and Prospects." Building Science, 28 (4): 1-7.

Van Bueren, E. M., and Priemus, H. (2002). "Institutional barriers to sustainable construction." Environment and Planning, 29(1), 75-86.

Williams, K., and Dair, C. (2007). "What is stopping sustainable building in England? Barriers experienced by stakeholders in delivering sustainable developments." Sustainable development, 15(3), 135-147.

Zhang B., Zhang L. (2010). Problems Encountered on Green Building Development in Tangshan City. Energy Research and Management, 3: 56-67.

Zhang H., Tian M. (2007). “Reliability analysis in the application of questionnaire design." Journal of statistics and decision., 249(21), 25-27.

Zhang X, Platten A, and Shen L.(2011) Green property development practice in China: costs and barriers. Building and Environment, 46(11): 2153-2160.

Zhang X., Shen L., Tam, V. W., and Lee, W. W. Y. (2012). Barriers to implement extensive green roof systems: a Hong Kong study. Renewable and Sustainable Energy Reviews, 16(1), 314-319.

Zhao Y., Tang H. (2010). Thought about Green Building and Sustainable Development. Building Science, 2010, 7: 85 .

Zhou Y., Zhang X.(2007). Research on Green Building's Development in China. Infrastructure Optimization, 28 (5): 132-133. 